\title{
Avaliação de ações impactantes em uma Reserva Biológica da região Nordeste do Brasil
}

\author{
Evaluation of impactful actions in a Biological Reserve in the Northeast of Brazil
}

\author{
Isabella Moura Carvalho Lima' \\ Laura Jane Gomes ${ }^{2}(*)$ \\ Paulo Faiad ${ }^{3}$
}

\section{Resumo}

A Reserva Biológica de Santa Isabel, importante sítio reprodutivo de quatro espécies de tartarugas marinhas brasileiras e com ecossistemas de significativa importância biológica, desde a sua criação vem sendo alvo de descumprimentos da legislação, o que pode comprometer os propósitos para os quais foi criada. Neste sentido, o estudo objetivou a identificação de ações impactantes e avaliação dos impactos decorrentes na REBIO, como forma de subsidiar ações de manejo e apontar as possibilidades para mitigação dos impactos ambientais negativos. Foram realizadas cinco visitas a campo para constatação das ações impactantes, e os impactos decorrentes foram qualificados por meio da Matriz de Leopold adaptada para os propósitos do estudo. Foram identificadas cinco ações impactantes, a saber: Tráfego de veículos; Turismo e Recreação; Uso do solo; Ocupação irregular e Acúmulo de Resíduos Sólidos. As ações encontram-se distribuídas por vinte e seis pontos dentro da REBIO, nos quais foram qualificados onze impactos negativos. É possível evidenciar que a unidade se encontra em um cenário de atividades conflitantes com os objetivos da sua categoria, e a ausência do plano de manejo, a insuficiência de servidores e recursos financeiros, e carência no envolvimento das comunidades foram os principais fatores atribuídos a essas ameaças. Recomenda-se a ampliação de medidas de educação ambiental e envolvimento da comunidade para mitigar os impactos negativos. Considera-se urgente o processo de regularização fundiária para a retirada das propriedades e recuperação de áreas degradadas em consequência do gado e cultivos agrícolas.

Palavras-chave: Plano de Manejo. Impacto Ambiental. Reserva Biológica de Santa Isabel. Matriz de Leopold. Unidade de Conservação.

1 Me.; Desenvolvimento e Meio Ambiente (PRODEMA); Universidade Federal de Sergipe, UFS, Brasil; Desenvolve pesquisas na linha de conservação da biodiversidade; carvalholimaisabella@gmail.com

2 Dra.; Engenharia Agrícola; Universidade Estadual de Campinas, UNICAMP, Brasil; Professora Associada da Universidade Federal de Sergipe, Departamento de Ciências Florestais; Endereço: Universidade Federal de Sergipe, Departamento de Ciências Florestais. Av. Marechal Rondon, s/n, Rosa Elze. CEP: 49100000 - Sao Cristovao, SE Brasil; E-mail: laurabuturi@gmail.com $\left(^{*}\right)$ Autor para correspondências

3 Me.; Gestão de Áreas Protegida; Instituto Nacional de Pesquisas da Amazônia, INPA, Brasil; Analista Ambiental do Instituto Chico Mendes de Conservação da Biodiversidade - ICMBio; Endereço: Instituto Chico Mendes de Conservação da Biodiversidade. Quadra SHIN QL 9 Conjunto 1, Setor de Habitações Individuais Norte; CEP: 71515215 - Brasília,

DF - Brasil; E-mail: paulo.faiad@icmbio.gov.br

\begin{tabular}{llllll}
\hline Ambiência & Guarapuava (PR) & v.15 n.I & p. $19-39$ & Jan/Abr 2019 & ISSN I808 - 025I
\end{tabular}




\section{Abstract}

The Santa Isabel Biological Reserve, an important breeding site for four species of threatened Brazilian sea turtles and occurrence area of ecosystems with significant biological importance, presents weaknesses in fulfilling its legal objectives, which could compromise the purposes of its creation. In this sense, the study aimed to identify and evaluate impactful actions in the protected area, in order to support management actions and mitigate the negative environmental impacts. Five field visits were conducted for verification of impactful actions and these were described using the modified Leopold Matrix and establishing a map, plotting points of occurrences of five identified actions, namely: vehicle traffic; Tourism and Recreation; Use of the soil; Irregular occupation and disposal of solid waste. These actions were distributed for twenty-six points in the Reserve map, and there were eleven negative impacts qualified. Thus, it is possible to show that this protected area is a scenario of conflicting activities with the objectives of its category, and the absence of a management plan, the insufficiencies of human and financial resources, and a lack in the involvement of communities were the main factors attributed for these threats. It is recommended the continuous expansion of environmental education actions and increasing of the community involvement to mitigate these negative impacts. It is considered urgent the land regularization process promoting the removal of farms and the recuperation of degraded areas occupied by livestock and crops.

Keywords: Management Plan. Environmental impact. Santa Isabel Biological Reserve. Matrix Leopold. Protected Areas.

\section{Introdução}

A perda de biodiversidade em todo o mundo vem sendo continuamente observada, não apenas pela extinção de espécies, mas também pela redução populacional de fauna e flora e, sobretudo, pela perda de ecossistemas inteiros (GANEM, 2010).

Como forma de conter a perda de diversidade biológica e proteger os recursos naturais, medidas como a criação de áreas protegidas foram instituídas em diversos países. No Brasil, o cenário não foi diferente e, na década de 90, já se apontava a necessidade de implantação de um Sistema Nacional de Unidades de Conservação (SNUC) visando frear os impactos da tendência expansionista e do uso imprevidente dos recursos naturais. Pode-se afirmar que a política de criação de áreas protegidas se tornou, no Brasil, a principal política de conservação da natureza (DRUMMOND, 1997; PÁDUA, 1997; 2011).

Contudo, ainda que, dentre as áreas protegidas, o número de Unidades de Conservação (UC) tenha crescido, para Bensusan (2006), a biodiversidade está continuamente ameaçada, em virtude dos desafios na implementação destas áreas. Alguns fatores contribuem para uma inadequação do sistema de unidades de conservação em todo o mundo, como por exemplo: o não cumprimento de objetivos de conservação da biodiversidade e a insuficiência na participação de comunidades locais na criação e administração dessas áreas. 
No modelo brasileiro, a falta de recursos humanos e financeiros constitui um problema crônico, em que inúmeras unidades de conservação existem apenas "no papel”, sem que ao menos seus planos de manejo sejam elaborados. Isso facilita a tendência de uma série de ameaças diretas e indiretas nessas áreas, como a perda e fragmentação de habitats, a propagação de espécies exóticas invasoras, o crescimento populacional, entre outros impactos negativos relacionados com a atividade humana (MEDEIROS; IRVING; GARAY, 2004; MONTREAL, 2004).

A Reserva Biológica (REBIO) de Santa Isabel, no estado de Sergipe, foi criada com o intuito principal de proteção à fauna local, sendo o principal sítio reprodutivo da tartaruga oliva Lepidochelys olivacea (Eschscholtz, 1829), no Brasil (BRASIL, 1988; CASTILHOS et al., 2011), além de possuir registros de outras três tartarugas marinhas que ocorrem na costa brasileira. A área possui ecossistemas de significativa importância biológica, como vegetação de restinga, cordões de dunas móveis e fixas, lagoas permanentes e temporárias e manguezais.

A categoria de Reserva Biológica está prevista na Lei no 9.985/2000 (Lei do SNUC), como área de proteção integral, em que é proibida a visitação pública e o uso direto de recursos (BRASIL, 2000). Não obstante, agricultores, pecuaristas, pescadores e turistas fazem uso da REBIO de Santa Isabel, o que pode estar comprometendo os objetivos de sua criação, com consequências para sua efetividade de conservação.

Apesar de ter sido criada em 1988, a UC ainda não possui plano de manejo, e o conselho consultivo, obrigatório para as reservas biológicas e de fundamental importância para a gestão, foi criado somente em 2015. O não estabelecimento de zonas em uma UC, ato previsto no plano, principalmente a zona de amortecimento, na qual as atividades humanas devem estar sujeitas a normas e restrições específicas, gera consequências que podem ser impactantes para a unidade e, assim, causar o descumprimento do seu objetivo de preservação integral da biodiversidade.

Desta forma, justifica-se a elaboração do presente estudo, com a identificação das possíveis ações impactantes na área da REBIO e qualificação dos impactos, o que poderá subsidiar futuras ações de manejo da Unidade de Conservação. Nesse sentido, este trabalho teve como objetivos i) identificar as ações impactantes na REBIO de Santa Isabel, além de qualificar os impactos, como forma de nortear as ações de manejo da unidade; ii) discutir sobre incompatibilidades de usos recorrentes em uma área de categoria de proteção integral e iii) apontar as possibilidades para a minimização dos impactos ambientais negativos visando à melhoria de sua efetividade.

\section{Material e Métodos}

A área de estudo compreende a Reserva Biológica de Santa Isabel, criada através do Decreto no 96.999/1998 e administrada pelo Instituto Chico Mendes de Conservação da Biodiversidade (ICMBio). A REBIO está localizada no litoral norte do estado de Sergipe, abrangendo os municípios de Pacatuba e Pirambu, a qual ocupa $45 \mathrm{~km}$ de praias e possui 4.109 hectares de área total (Figura 1). 


\section{Figura 1 - Localização da Reserva Biológica de Santa Isabel, Sergipe}

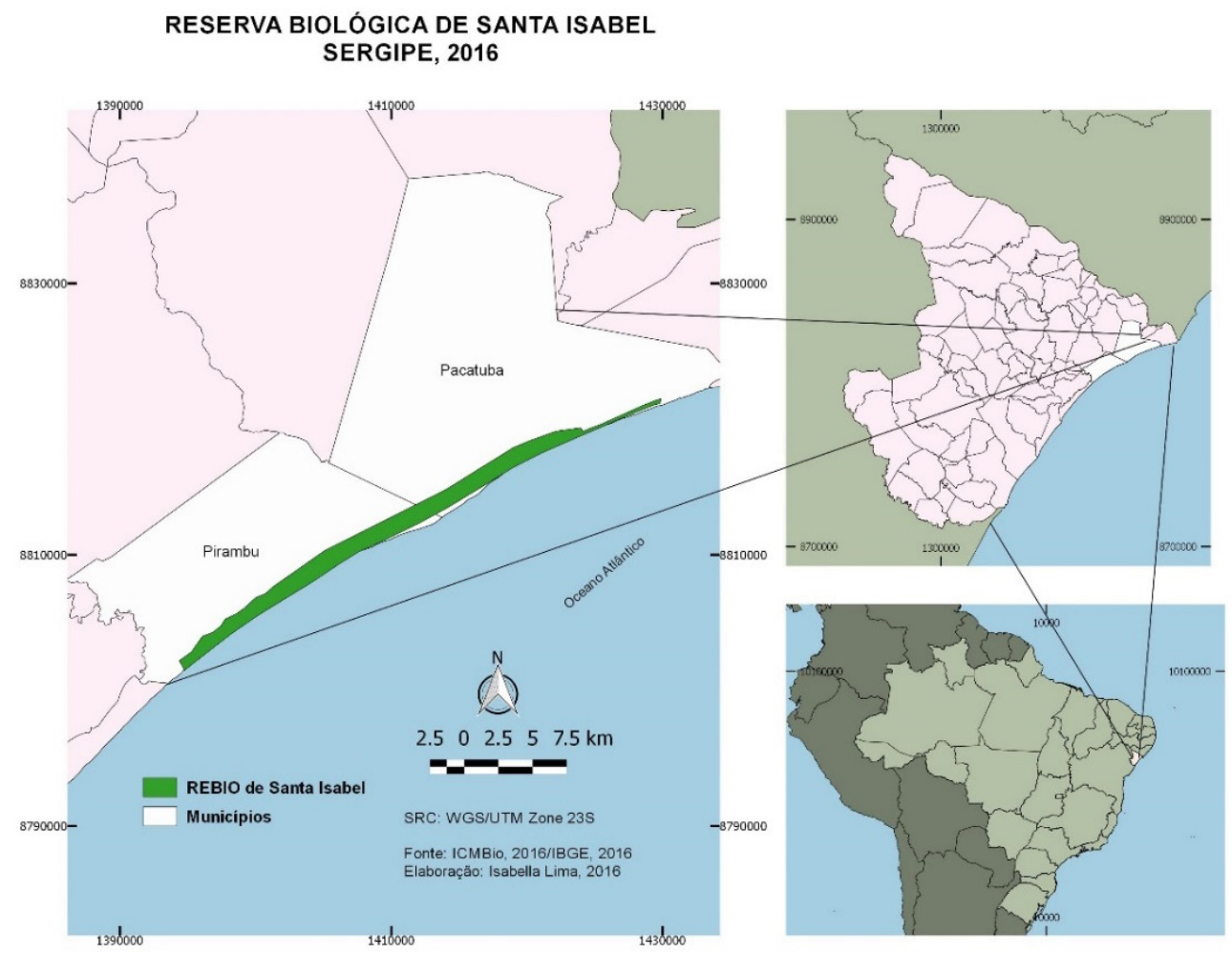

Fonte: Elaboração dos autores.

A UC possui remanescentes de Mata Atlântica em seu interior, e as principais fitofisionomias vegetais que compõem a área são: i) Formações Herbáceas; ii) Restinga, subdividida em Restinga Arbustiva, Restinga Arbustivo-Arbórea e Restinga Arbórea; e iii) Lagoas, Manguezais e Coqueirais (MMA, 2015). No tocante à fauna, cumpre destacar a presença de quatro espécies de tartarugas marinhas na REBIO de Santa Isabel, do total de cinco espécies que ocorrem na costa brasileira.

Outras espécies de ocorrência restrita são presentes na área, tais como: o lagarto Tropidurus bygomi (Reinhardt e Luetken, 1861), endêmico de áreas de restinga; o jacaré-do-papo-amarelo Caiman latirostris (Daudin, 1802); a perereca Phyllodytes punctatus (Caramaschi e Peixoto, 2004), a qual teve, na REBIO, o primeiro registro da espécie fora de sua localidade-tipo e o primeiro dentro de uma UC (CARAMASCHI; PEIXOTO, 2004); e o Scinax agilis (Cruz e Peixoto, 1983), uma das únicas quatro espécies de anfíbios endêmicas de áreas de restinga e com o primeiro registro da espécie para o estado de Sergipe na REBIO.

Com relação à hidrografia, destaca-se a presença do rio Betume, afluente do rio São Francisco, no extremo norte da REBIO. O rio apresenta curso paralelo ao polígono da REBIO e, em períodos chuvosos, favorece a formação de lagoas adjacentes à unidade, ao longo de parte de seu limite oeste.

\section{Coleta e análise de dados}

Para a identificação das ações impactantes na REBIO, foram executadas cinco visitas a campo, no período entre maio de 2015 e março de 2016, com duração de aproximadamente três horas cada visita, em diferentes dias. A área da unidade foi percorrida com um quadriciclo 
do ICMBio, e observações in loco foram feitas para identificação das ações. A busca foi feita de forma direcionada, em locais previamente conhecidos pelo gestor da unidade. Nos pontos em que se constataram ações impactantes, registros fotográficos foram efetuados e os pontos foram georreferenciados com o auxílio do GPS Garmin 76csx, Datum Wgs84. Foram percorridos aproximadamente $90 \mathrm{~km}$ da unidade em cada visita, em sua extensão litorânea, e adentrou-se, também, em sua largura, no sentido da linha de preamar para o continente.

Os impactos decorrentes das ações registradas foram qualificados com base na Matriz de Leopold (SANTOS, 2007), modificada com parâmetros qualitativos. Convém ressaltar que, apesar de a Matriz de Leopold ter sido criada para a Avaliação de Impactos Ambientais no processo de licenciamento ambiental, a ferramenta tem se mostrado eficaz para estudos de planejamento e avaliação ambiental em UC's, por possibilitar uma abordagem sistêmica e interdisciplinar das relações entre as ações impactantes, os impactos, os meios e a qualificação dos impactos, fornecendo informações para subsidiar a gestão de uma unidade (SOBRAL et al., 2007; SANTOS et al.,2013).

Foram considerados os impactos aos meios físico, biótico, antrópico e paisagístico, a depender de cada ação. Os impactos foram registrados a partir de observações dos efeitos diretos, e no caso dos impactos prováveis, utilizaram-se dados de revisão bibliográfica, adequando-os para a área de estudo. A análise das ações impactantes foi organizada em quadros para melhor visualização dos resultados.

Os impactos foram qualificados em função das seguintes características (SANTOS, 2007):

i) Frequência: define a sazonalidade do impacto, que pode ser caracterizado como: temporário $(\mathrm{T})$, quando o efeito do impacto se manifesta por um determinado tempo após a realização da ação; permanente (PR), quando uma vez executada a ação, os efeitos continuam a manifestar-se em um horizonte temporal conhecido; ou cíclico (C), quando o efeito se faz sentir em determinados períodos (ciclos), que podem ser ou não constatados ao longo do tempo.

ii) Extensão: determina a abrangência da área atingida, sendo o impacto local, quando a ação afeta apenas o próprio sítio e suas imediações e o impacto regional, quando se estende além das imediações do sítio onde se provocou a ação.

iii) Reversibilidade: refere-se ao retorno do ambiente às condições originais, sendo caracterizado como impacto irreversível, quando o fator ou parâmetro ambiental, ao sofrer a ação do impacto, não retorna as condições originais; e como impacto reversível quando cessada a ação, o fator ou parâmetro ambiental retorna às suas condições originais.

iv) Duração: determina o tempo efetivo do impacto, que pode ser classificado como: de curto prazo, quando seus efeitos têm duração de até 1 ano; de médio prazo, quando seus efeitos têm duração de 1 a 10 anos e de longo prazo, quando seus efeitos têm duração de 10 a 50 anos.

v) Origem: trata da posição do impacto numa cadeia de reações, caracterizando-se como impacto direto, quando é resultante de uma simples relação de causa e efeito ou impacto indireto, quando é parte de uma cadeia de reações.

vi) Sentido: atribui valor ao impacto, que pode ser classificado como benéfico, quando a ação resulta na melhoria de fatores ambientais; e adverso ou negativo, quando ação resulta em um dano à qualidade de um ou mais fatores ambientais.

vii) Grau de Impacto: é o critério de classificação usado para indicar a gravidade do impacto no meio ambiente, que pode ser: baixo (B), quando a utilização dos recursos naturais é desprezível quanto ao seu esgotamento, sendo reversível; médio (M), quando a utilização de recursos naturais é considerada, sem que haja possibilidade de esgotamento dos recursos naturais, 
sendo a degradação do meio ambiente um processo reversível, porém com ações imediatas; alto (A), quando a ação provoca a escassez de recursos naturais e a degradação de fatores ambientais, diminuindo as probabilidades de reversibilidade.

\section{Resultados e Discussão}

\section{Ações impactantes}

Foram constatadas cinco ações impactantes na REBIO de Santa Isabel, a saber: Tráfego de veículos; Recreação e Turismo; Uso do solo; Ocupação irregular e Acúmulo de resíduos sólidos. Essas ações foram encontradas distribuídas em vinte e seis pontos na extensão da REBIO de Santa Isabel.

\section{Tráfego de veículos}

Foram identificados seis acessos para a entrada de veículos pela praia. Merece destaque o acesso para a entrada da área de Lagoa Redonda, que apresentou uma concentração de veículos estacionados. Isso se deve ao fato de essa região ser um dos pontos mais procurados para o turismo. Além disso, é frequente o uso de sons automotivos nesta região, estendendo o problema para um caso de poluição sonora, tanto dentro da área, como no entorno. Existe um ponto de intersecção que apresenta o acesso para os visitantes advindos de povoados do município de Pacatuba, como Tigre, Estiva do Raposo e Timbó. Outros três pontos constituem porteiras de entrada dos visitantes que têm propriedade no entorno da reserva, principalmente, com emprego de veículos do tipo quadriciclos.

Segundo Saunders et al. (2000), a circulação de veículos é uma das pressões exercidas nas praias pelas atividades recreativas que podem causar impactos negativos. Os impactos para o meio físico são decorrentes de uma força exercida que pode resultar na compactação do sedimento, causando uma desestabilização que o torna mais vulnerável à erosão por processos naturais. Ademais, destaca-se a emissão de gases nocivos, e a poluição sonora, ambos qualificados, neste estudo, como impactos negativos de médio grau (Quadro 1).

Para o meio biótico, os veículos provocam o afugentamento da fauna, impacto qualificado como de alto grau, tendo em vista a importância biológica da área (Quadro 1). O afugentamento resulta de perturbações causadas pelo deslocamento, por vezes veloz, dos veículos; e de ruídos emitidos pelos veículos, que podem alterar comportamentos territoriais, de reprodução e outras interações sociais. 


\section{Quadro 1- Qualificação dos impactos decorrentes do tráfego de veículos na REBIO de Santa Isabel, SE.}

\begin{tabular}{ccc}
\hline MEIO & IMPACTO & QUALIFICAÇÃO DOS IMPACTOS \\
\hline & Compactação do sedimento & $\begin{array}{c}\text { Temporário; Local; Reversível; Curto prazo de } \\
\text { resposta; Direto; Adverso; Médio grau de impacto }\end{array}$ \\
\cline { 2 - 3 } & Aumento dos fenômenos erosivos & $\begin{array}{c}\text { Permanente; Local; Reversível; Médio tempo de } \\
\text { resposta; Indireto; Adverso; Alto grau de impacto }\end{array}$ \\
\cline { 2 - 3 } & Poluição sonora & $\begin{array}{c}\text { Temporário; Local; Reversível; Curto prazo de } \\
\text { resposta; Direto; Adverso; Médio grau de impacto }\end{array}$ \\
\cline { 2 - 3 } & $\begin{array}{c}\text { Aumento da concentração de } \\
\text { gases nocivos }\end{array}$ & $\begin{array}{c}\text { Cíclico; Regional; Reversível; Curto prazo de } \\
\text { resposta; Indireto; Adverso; Médio grau de impacto }\end{array}$ \\
\cline { 2 - 3 } & $\begin{array}{c}\text { Afugentamento da fauna } \\
\text { Degradação da cobertura vegetal }\end{array}$ & $\begin{array}{c}\text { Temporário; Local; Irreversível; Curto prazo; Direto; } \\
\text { Adverso; Médio grau de impacto }\end{array}$ \\
\cline { 2 - 3 } & $\begin{array}{c}\text { Compactação dos ninhos de } \\
\text { tartarugas marinhas }\end{array}$ & $\begin{array}{c}\text { Temporário; Local; Reversível; Curto prazo; Direto; } \\
\text { Adverso; Alto grau de impacto }\end{array}$ \\
\hline $\begin{array}{c}\text { Obstáculo para tartarugas } \\
\text { marinhas }\end{array}$ & $\begin{array}{c}\text { Temporário; Local; Reversível; Curto prazo; Direto; } \\
\text { Adverso; Alto grau de impacto }\end{array}$ \\
\hline $\begin{array}{c}\text { Atropelamento de fêmeas e } \\
\text { filhotes de tartarugas marinhas }\end{array}$ & $\begin{array}{c}\text { Temporário; Local; Irreversível; Curto prazo; Direto; } \\
\text { Adverso; Alto grau de impacto }\end{array}$ \\
\hline
\end{tabular}

Fonte: Elaborado pelos autores

A compactação dos ninhos de tartarugas marinhas, o obstáculo no alcance de filhotes ao mar e o atropelamento de fêmeas e filhotes foram outros impactos registrados para a fauna local. Saunders et al. (2000) divulgaram um estudo realizado em ecossistemas marinhos europeus protegidos em áreas de conservação, no qual analisaram os potenciais efeitos de atividades recreativas sobre as espécies e o habitat. Os autores citados acima destacaram os impactos negativos dos veículos sobre as aves costeiras e sobre a desova de tartarugas marinhas. $\mathrm{O}$ fato de a REBIO de Santa Isabel ser uma importante área em desova de quatro tartarugas marinhas brasileiras, todas ameaçadas de extinção, agrava as consequências dessa atividade. $\mathrm{O}$ trânsito de veículos, ao causar compactação dos ninhos em incubação, prejudica o nascimento dos filhotes e a sua saída dos ninhos e dificulta o acesso dos filhotes ao mar, em virtude das marcas de pneus deixadas (SANTOS et al., 2011).

A degradação da cobertura vegetal corresponde a outro impacto ambiental negativo identificado, em decorrência da atividade de tráfego de veículos (Quadro 1). Brown e McLachlan (1990) ressaltam que essa degradação, causada por pressões exercidas pelos veículos e abertura de trilhas, aumenta ainda mais os fenômenos de desestabilização e erosão das dunas. Oliveira e Souza (2005) já haviam identificado processos iniciais de degradação ao sistema dunar na REBIO de Santa Isabel, e o trânsito de veículos foi uma das atividades antrópicas relacionadas a este impacto.

A sinalização e a demarcação deficientes da UC podem ser algumas das causas para a frequente presença de veículos na área. A indefinição dos limites da UC, um resultado de falhas técnicas na instituição do polígono da unidade, dificulta o estabelecimento de placas e demarcação da área. Ainda assim, a falta de placas indicando os limites da REBIO não impossibilita a proibição da atividade, já que independente de ser uma unidade de conservação de proteção integral, o 
artigo $1^{\circ}$ da Portaria IBAMA no 10 de 1995 pró́be o trânsito de qualquer veículo na faixa de praia no estado de Sergipe (BRASIL, 1995).

Dessa forma, faz-se indispensável o desenvolvimento de medidas de educação ambiental para a comunidade, a fim de possibilitar a compreensão dos motivos pelos quais não se permite o trânsito de veículos nas praias, atreladas a ações repressivas para os atos que ferem a legislação e comprometem a efetividade da REBIO de Santa Isabel. No entanto, as ações de fiscalização e monitoramento deverão acontecer paralelamente.

\section{Recreação e turismo}

As atividades turísticas e recreativas na REBIO são amplamente realizadas, o que constitui um ato que contradiz com os objetivos da categoria, posto que a Lei do SNUC (BRASIL, 2000) prevê a proibição da visitação pública nesta categoria. Figueira (2011, p. 4) afirma que "as atividades turísticas em áreas protegidas são anteriores à sua própria existência”. O autor atribui a necessidade das pessoas relacionados ao desfrute de um ambiente particular e contemplação da natureza como um dos fatores para a origem dessas atividades turísticas e recreativas. No entanto, Mendes et al. (2002) apontam o turismo desordenado como uma das causas para conflitos de uso na zona costeira.

Foram identificadas três regiões dentro da REBIO com maior atividade turística, a saber: Praia de Pirambu, Lagoa Redonda e Praia de Ponta dos Mangues. Em Lagoa Redonda, um fator que se torna incentivo para o turismo é a presença de barracas de comercialização, bares e restaurantes dentro dos limites da reserva, o que problematiza ainda mais a situação.

Nos sistemas dunares, marcantes na área da REBIO, foram observados visitantes, seja para contemplação do local, ou para práticas de sandboard (surf de areia). A ação de pisoteio das dunas causa uma alteração da ecodinâmica costeira, qualificada como um impacto reversível ao meio físico, porém de alto grau (Quadro 2). A manutenção da ecodinâmica das dunas é definida como um equilíbrio entre os processos de acreção dunar - acúmulo de sedimentos; e erosão dunar retirada de sedimentos. Oliveira e Souza (2012) indicam as atividades recreativas supracitadas como causadoras de uma possível interferência no processo de acreção dunar, onde se tem meios instáveis, além de alteração na morfologia praial.

Apesar de apresentar certa estabilidade nos estudos realizados, a intensificação desses processos, para as autoras supracitadas, tornaria o quadro de alimentação de sedimentos deficitário e causaria uma mudança nessa estabilidade. Além disso, o pisoteio de dunas foi registrado como 
uma ação impactante que facilita a degradação de materiais arqueológicos, estes presentes na REBIO de Santa Isabel e de grande relevância histórica e cultural (Quadro 2).

\section{Quadro 2 - Ações Impactantes, meio, impacto e qualificação dos impactos decorrentes do pisoteio e da ocupação dos turistas na REBIO de Santa Isabel, SE.}

\begin{tabular}{|c|c|c|c|}
\hline AÇÃO & MEIO & IMPACTO & $\begin{array}{l}\text { QUALIFICAÇÃO } \\
\text { DOS IMPACTOS }\end{array}$ \\
\hline \multirow{3}{*}{ Pisoteio } & \multirow{2}{*}{$\frac{0}{U}$} & $\begin{array}{l}\text { Alteração da } \\
\text { ecodinâmica } \\
\text { costeira }\end{array}$ & $\begin{array}{c}\text { Permanente; Local; } \\
\text { Reversível; Médio prazo; } \\
\text { Indireto; Adverso; Alto } \\
\text { grau de impacto }\end{array}$ \\
\hline & & $\begin{array}{l}\text { Ação mecânica } \\
\text { e degradação } \\
\text { de materiais } \\
\text { arqueológicos }\end{array}$ & $\begin{array}{l}\text { Permanente; Local; } \\
\text { Irreversível; Médio prazo; } \\
\text { Indireto; Adverso; Médio } \\
\text { grau de impacto }\end{array}$ \\
\hline & 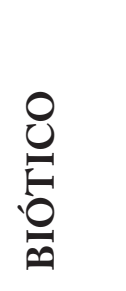 & $\begin{array}{c}\text { Alteração da } \\
\text { cobertura vegetal }\end{array}$ & $\begin{array}{l}\text { Permanente; Local; } \\
\text { Irreversível; Médio prazo; } \\
\text { Indireto; Adverso; Alto } \\
\text { grau de impacto }\end{array}$ \\
\hline \multirow{4}{*}{$\begin{array}{l}\text { Ocupação } \\
\text { das áreas }\end{array}$} & \multirow{4}{*}{$\begin{array}{l}0 \\
0 \\
0 \\
0 \\
0 \\
0\end{array}$} & $\begin{array}{l}\text { Afugentamento da } \\
\text { fauna }\end{array}$ & $\begin{array}{c}\text { Temporário; Local; } \\
\text { Reversível; Curto prazo; } \\
\text { Direto; Adverso; Alto grau } \\
\text { de impacto }\end{array}$ \\
\hline & & $\begin{array}{c}\text { Obstáculo } \\
\text { para tartarugas } \\
\text { marinhas }\end{array}$ & $\begin{array}{c}\text { Temporário; Local; } \\
\text { Reversível; Curto prazo; } \\
\text { Direto; Adverso; Alto grau } \\
\text { de impacto }\end{array}$ \\
\hline & & $\begin{array}{l}\text { Compactação } \\
\text { dos ninhos em } \\
\text { incubação }\end{array}$ & $\begin{array}{c}\text { Temporário; Local; } \\
\text { Reversível; Curto prazo; } \\
\text { Direto; Adverso; Alto grau } \\
\text { de impacto }\end{array}$ \\
\hline & & $\begin{array}{l}\text { Interferência na } \\
\text { temperatura de } \\
\text { incubação dos } \\
\text { ninhos }\end{array}$ & $\begin{array}{l}\text { Cíclico; Local; Reversível; } \\
\text { Curto prazo; Direto; } \\
\text { Adverso; Médio grau de } \\
\text { impacto }\end{array}$ \\
\hline
\end{tabular}

Fonte: Elaborado pelos autores.

No tocante à ação de ocupação direta dos turistas com emissão de ruídos, foram identificados quatro impactos ao meio biótico (Quadro 2). Para a fauna em geral, a ação provoca afugentamento, e comportamentos de forrageamento, reprodução e interação social as quais podem ser alterados em virtude de perturbações humanas nestes locais. Especificamente para as tartarugas marinhas, os impactos identificados para esta atividade são a compactação dos ninhos, causada pelo trânsito de pessoas na praia e obstáculos no acesso de filhotes ao mar e de fêmeas para a desova, causados por mesas de praia e guarda-sóis. Segundo Santos et al. (2011), estes objetos, ademais, devido ao 
sombreamento propiciado causam outro impacto: a interferência na temperatura de incubação dos ninhos, considerado, na presente pesquisa, como impacto provável resultado desta ação identificada.

O turismo dentro da reserva biológica é incentivado, por vezes, por meios midiáticos reconhecidos em rede nacional, o que constitui em outro problema, já que a população resulta por ter acesso a informações errôneas sobre essas áreas. A mídia etiqueta, principalmente Ponta dos Mangues e Lagoa Redonda, como locais paradisíacos para a contemplação da natureza e descanso. Ainda acontece a divulgação de passeios que ocorrem no local, como citado:

"O caminho de areia traçado pelo vento revela $20 \mathrm{~km}$ de dunas douradas que se movimentam o tempo todo. Os guias são moradores da região e levam os turistas a lugares no meio das dunas cobertos pela vegetação nativa, onde é possível ver o descanso de um belo lagarto. O passeio, com três horas com um guia, custa $\mathrm{R} \$ 50$ ” [SUZANNE, 2014]

Além da divulgação na mídia, a REBIO foi rotulada como destino turístico em um trabalho científico (ANDRADE et al., 2014), em que consta:

Os principais pontos turísticos que o visitante pode utilizar para o lazer são: Praça da Folia, Praias, Reserva biológica de Santa Isabel, que é o berçário das tartarugas marinhas (Projeto TAMARIBAMA), cachoeiras, rios, orlas e dunas.

[...] Na Lagoa Redonda, por exemplo, os turistas aproveitam as ondulações para descerem o areal escorregadio sentados na madeira em forma de prancha [...]" (ANDRADE et al, 2014, p. 16-17, grifo nosso)

Esse ponto direciona a situação para um estado mais crítico ainda. A qualificação dos impactos causados pelo turismo mostra que os efeitos são, em sua grande parte, adversos ao meio ambiente. Entretanto, cabe ressaltar que esse turismo é desenvolvido de forma desordenada, sem planejamentos, com concentração em pontos específicos da REBIO de Santa Isabel, contribuindo para esta adversidade. Lickorish e Jenkins (2000) salientam os diversos impactos negativos, muitos deles irreversíveis, que o turismo pode causar; contudo defendem que não é o desenvolver da atividade que gera degradação do meio, e sim a falta de planejamento.

Ainda assim, mesmo que esse turismo viesse a ser desenvolvido sem impactar o ambiente de forma negativa, o incentivo ao lazer dentro dessas áreas contraria um objeto jurídico, pois, como já citado, a categoria de REBIO é a mais restritiva para o uso público. O "Roteiro Metodológico de Planejamento”, documento oficial que direciona os planos de manejo de Reservas Biológicas, Estações Ecológicas e Parques Nacionais, dispõe que, no caso das reservas biológicas, é possível apenas a destinação de pequenas trilhas para atividades de educação ambiental, o que não se aplica a este caso (MMA, 2002).

Sugere-se uma maior distribuição de informações para a comunidade, com ciclos de palestras e visitas orientadas, envolvendo a população, comunidade científica e meios midiáticos para uma maior abrangência. $\mathrm{O}$ impedimento imediato das atividades de lazer pode causar sérios conflitos com a comunidade, que utiliza o local há décadas. Torna-se inviável e pouco efetivo o cumprimento da lei de forma brusca, sem a união de medidas educativas, neste caso, já que resultaria em uma exclusão da participação pública, fator necessário para a conservação ambiental. 
Assim, recomenda-se a destinação de recursos para a criação de exposições interativas no Centro de Educação Ambiental situado na sede da unidade. Essas informações podem esclarecer questões sobre as UC's de forma geral, elucidar as diferentes categorias existentes, bem como sobre a REBIO de Santa Isabel, os motivos de este local ser enquadrado em uma área protegida, suas restrições e a importância da sua conservação. Recomenda-se também que o órgão gestor busque articulação juntamente à Secretaria de Estado de Turismo e secretarias municipais, a fim de buscar um diálogo e formas de conciliar o turismo de acordo com os atributos locais.

\section{Uso do solo}

Duas ações impactantes nos ambientes de dunas foram identificadas: atividades agrícolas (cultivo de coco-da-baía) e pastagens para gado.

a) Gado

Foi constatado que a criação de gado ocorre ao longo da REBIO, com intenso uso do solo para pastagens de gado que abrange uma área de $16 \mathrm{~km}$ dentro da unidade. Os rebanhos foram encontrados em porções antidunas, baixios e zonas interdunares, e há predomínio de bois e cabras.

O gado causa impactos ao meio físico e biótico de duas principais formas: pelo pisoteio e pela herbivoria, sendo que os impactos aos dois meios estão diretamente relacionados. A herbivoria e pisoteio alteram a composição e abundância de espécies da cobertura vegetal (HEWETT, 1985), o que influencia na paisagem das dunas, causando uma alteração na ecodinâmica costeira e aumento dos fenômenos erosivos, resultado de mudanças na deposição de areia. Além disso, há a emissão de gases nocivos para a atmosfera, como o metano, por bovinos e ovinos, resultado dos processos metabólicos destes animais.

Outro impacto é a facilitação para o surgimento de espécies exóticas, resultado da perturbação no habitat que cria novos espaços; e introdução de sementes através dos excrementos (ROSA; CORDAZZO, 2007). Bois e carneiros são comumente encontrados soltos, pastando na REBIO, o que provoca alterações no comportamento da fauna nativa, que leva ao afugentamento nas regiões de ocupação do gado (Quadro 3).

\section{Quadro 3 - Qualificação dos impactos decorrentes da presença do gado na REBIO de Santa Isabel, SE.}

\begin{tabular}{|c|c|c|}
\hline MEIO & IMPACTO & QUALIFICAÇÃO DOS IMPACTOS \\
\hline \multirow{2}{*}{ FÍSICO } & $\begin{array}{l}\text { Alteração na ecodinâmica } \\
\text { costeira; aumento dos } \\
\text { fenômenos erosivos }\end{array}$ & $\begin{array}{l}\text { Cíclico; Local; Irreversível; Médio prazo; Indireto; } \\
\text { Adverso; Médio grau de impacto }\end{array}$ \\
\hline & $\begin{array}{l}\text { Aumento da concentração de } \\
\text { gases nocivos }\end{array}$ & $\begin{array}{l}\text { Cíclico; Regional; Reversível; Curto prazo de } \\
\text { resposta; Direto; Adverso; Alto grau de impacto }\end{array}$ \\
\hline \multirow{3}{*}{ BIÓTICO } & $\begin{array}{l}\text { Alteração da cobertura } \\
\text { vegetal }\end{array}$ & $\begin{array}{l}\text { Permanente; Local; Reversível; Médio prazo; Direto; } \\
\text { Adverso; Alto grau de impacto }\end{array}$ \\
\hline & $\begin{array}{l}\text { Facilitação para presença de } \\
\text { espécies exóticas }\end{array}$ & $\begin{array}{l}\text { Temporário; Local; Reversível; Curto prazo; Indireto; } \\
\text { Adverso; Médio grau de impacto }\end{array}$ \\
\hline & $\begin{array}{l}\text { Afugentamento da fauna } \\
\text { nativa }\end{array}$ & $\begin{array}{l}\text { Temporário; Local; Reversível; Curto prazo; Direto; } \\
\text { Adverso; Alto grau de impacto }\end{array}$ \\
\hline
\end{tabular}




\section{b) Cultivos agrícolas}

A atividade agrícola localizada no interior da REBIO de Santa Isabel é destinada ao cultivo de coco-da-baía - Cocos nucifera L. (Purseglove, 1981) Foram identificadas nove extensas áreas de coqueirais em propriedades particulares na REBIO de Santa Isabel, que totalizaram 172 hectares. Estas propriedades já existiam antes da criação da UC, e ainda não houve a devida desapropriação posto que os processos de regularização fundiária da REBIO. A maior área identificada totaliza 49,86 hectares, e corresponde à única área ocupada por moradores.

Segundo Cavalcanti (2000, p. 69),

a intensificação da ocupação agrícola das dunas vem provocando graves danos ambientais, pois esta unidade não é potencialmente apta para a exploração agrícola, devido principalmente à sua instabilidade geomorfológica, inexistência de solos férteis e baixa umidade superficial.

Ainda segundo a autora, as práticas agrícolas nestes ambientes provocam a contaminação do solo e das águas, com o lançamento de resíduos tóxicos; aumento do processo de erosão; diminuição do potencial de regeneração do solo; alterações nas espécies de flora e fauna nativas.

Embora seja verificada uma adaptação dos coqueiros aos ambientes litorâneos no geral, o cultivo do coco pode ocasionar uma série de problemas em virtude da composição edáfica da REBIO de Santa Isabel. O tipo de solo nesse ambiente é o neossolo quartizarênico, considerado de baixa aptidão agrícola, sendo rapidamente levado à degradação por uso contínuo. Por possuir insuficiência em matéria orgânica, não ocorre a agregação de partículas, o que eleva a suscetibilidade do solo à erosão. Outro problema é a lixiviação de nutrientes e a decomposição rápida da matéria orgânica, por causa da grande permeabilidade e porosidade dos solos arenosos (SPERA et al., 1999). Ainda que possuam elevada permeabilidade, estes solos apresentam limitações pela restrição de drenagem, devido à presença do lençol freático elevado durante grande parte do ano. Sendo assim, o cultivo do coco, na REBIO, é realizado com captações diretas das lagoas na área de drenagem do rio Aningas.

Para o presente estudo, portanto, consideraram-se impactos aos quatro meios: físico, biótico, paisagístico e antrópico. A descaracterização da paisagem natural foi considerada, pois apesar de os coqueirais serem amplamente remetidos à imagem da zona litorânea, trata-se de uma espécie exótica, já que não faz parte da flora nativa deste ecossistema; causando uma alteração na paisagem. No meio antrópico qualificou-se o impacto de benefícios socioeconômicos como positivo, em virtude de esta atividade ser uma das principais fontes de economia dos municípios do entorno da REBIO de Santa Isabel (Quadro 4). 
Quadro 4 - Qualificação dos impactos decorrentes do cultivo de coco-da-baía na REBIO de Santa Isabel, SE.

MEIO IMPACTO QUALIFICAÇÃO DOS IMPACTOS

\begin{tabular}{ccc}
\hline \multirow{2}{*}{ FÍSICO } & $\begin{array}{c}\text { Aumento dos fenômenos } \\
\text { erosivos }\end{array}$ & $\begin{array}{c}\text { Temporário; Local; Irreversível; Médio prazo; } \\
\text { Direto; Adverso; Médio grau de impacto }\end{array}$ \\
\cline { 2 - 3 } & Lixiviação de nutrientes & $\begin{array}{c}\text { Temporário; Local; Reversível; Médio prazo; } \\
\text { Indireto; Adverso; Baixo grau de impacto }\end{array}$ \\
\hline BIÓTICO & $\begin{array}{c}\text { Alteração da cobertura vegetal } \\
\text { nativa }\end{array}$ & $\begin{array}{c}\text { Cíclico; Local; Irreversível; Curto prazo; } \\
\text { Direto; Adverso; Médio grau de impacto }\end{array}$ \\
\hline \multirow{2}{*}{ PAISAGÍSTICO } & $\begin{array}{c}\text { Descaracterização da paisagem } \\
\text { natural }\end{array}$ & $\begin{array}{c}\text { Permanente; Local; Reversível; Curto prazo; } \\
\text { Direto; Adverso; Baixo grau de impacto }\end{array}$ \\
\hline \multirow{2}{*}{ ANTRÓPICO } & Benefícios socioeconômicos & $\begin{array}{c}\text { Cíclico; Regional; Reversível; Longo prazo; } \\
\text { Positivo; Médio grau de impacto }\end{array}$ \\
\hline
\end{tabular}

Fonte: Elaborado pelos autores.

Melo et al. (2011) constataram a existência de conflitos entre a comunidade e os órgãos ambientais envolvidos na gestão da unidade a partir de entrevistas com os moradores do entorno da área, os quais relataram autoritarismo dos órgãos quanto às restrições de uso dos recursos naturais na REBIO e no entorno. Neste sentido, a curto prazo, enquanto não for elaborado o Plano de Manejo da UC, sugere-se uma negociação com a comunidade para práticas do tipo, principalmente a pastagem do gado solto na restinga, com adoção de medidas de mitigação dos impactos.

A retirada do gado somente poderá ser legalmente efetuada quando o polígono com os reais limites da REBIO finalmente se dispuser oficial, podendo dar seguimento aos processos de desapropriação e regularização fundiária. Após a retirada do gado e dos cultivos agrícolas, é imprescindível a realização de estudos mais aprofundados para a criação de um plano de recuperação de áreas degradadas, a fim de restabelecer a cobertura vegetal nativa.

\section{Ocupação irregular}

A ocupação irregular dentro da REBIO com diversos fins foi registrada, e oito pontos foram identificados.

\section{Infraestrutura}

Um dos pontos abrange a área da Lagoa Redonda, a qual apresenta bares e restaurantes instalados; bem como barracas de palha destinadas à venda de bebidas e produtos alimentícios nos fins de semana, onde há um maior movimento de visitantes a procura de lazer. Durante a visita de campo, foi possível constatar a construção de banheiros em um dos bares, com a prática de extração de areia para tal feito.

A infraestrutura no geral causa impactos ao meio físico como a alteração na ecodinâmica costeira, em virtude de formar barreiras que alteram os movimentos naturais dos sedimentos litorâneos, dinâmica de dunas móveis, além de propiciar a compactação do solo. Na pesquisa de 
campo foi observada a construção de um banheiro próximo ao córrego. Assim, considerou-se a possível depreciação da qualidade da água como um impacto ao meio físico, indireto, adverso e de médio grau (Quadro 5).

Para o meio biótico, a presença de construções causa afugentamento da fauna, devido à concentração de pessoas, aumento de ruídos, e ainda, formação de obstáculos para a locomoção natural dos animais. $\mathrm{O}$ estabelecimento de bares e restaurantes provoca o incentivo ao turismo desordenado, fato que foi corroborado com a confirmação do maior fluxo de turistas em Lagoa Redonda frente aos outros pontos. Não obstante, considerou-se também um impacto positivo ao meio antrópico, a geração de benefícios sociais e econômicos (Quadro 5), porém que não se sustentam ao longo do tempo por não estar em consonância com os propósitos da UC.

\section{Quadro 5 - Qualificação dos impactos decorrentes da infraestrutura em Lagoa Redonda, REBIO de Santa Isabel, SE}

\begin{tabular}{|c|c|c|}
\hline MEIO & IMPACTO & QUALIFICAÇÃO DOS IMPACTOS \\
\hline \multirow{2}{*}{ 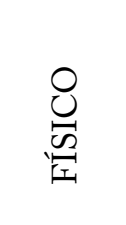 } & $\begin{array}{l}\text { Alteração na } \\
\text { ecodinâmica costeira }\end{array}$ & $\begin{array}{l}\text { Cíclico; Local; Irreversível; Médio prazo; } \\
\text { Indireto; Adverso; Alto grau de impacto }\end{array}$ \\
\hline & $\begin{array}{l}\text { Depreciação da } \\
\text { qualidade da água* }\end{array}$ & $\begin{array}{l}\text { Temporário; Regional; Reversível; Curto prazo; } \\
\text { Indireto; Adverso; Médio grau de impacto }\end{array}$ \\
\hline \multirow{2}{*}{ 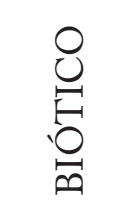 } & Afugentamento da fauna & $\begin{array}{l}\text { Temporário; Local; Reversível; Curto prazo; } \\
\text { Direto; Adverso; Médio grau de impacto }\end{array}$ \\
\hline & $\begin{array}{l}\text { Redução da biota do } \\
\text { solo** }\end{array}$ & $\begin{array}{l}\text { Temporário; Local; Reversível; Curto prazo; } \\
\text { Direto; Adverso; Baixo grau de impacto }\end{array}$ \\
\hline \multirow{3}{*}{ 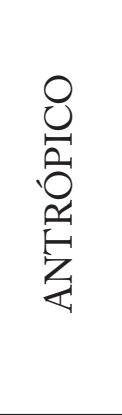 } & $\begin{array}{l}\text { Incentivo ao turismo } \\
\text { desordenado }\end{array}$ & $\begin{array}{l}\text { Temporário; Local; Reversível; Curto prazo; } \\
\text { Direto; Adverso; Médio grau de impacto }\end{array}$ \\
\hline & $\begin{array}{c}\text { Benefícios } \\
\text { socioeconômicos**** }^{* *}\end{array}$ & $\begin{array}{l}\text { Temporário; Local; Reversível; Curto prazo; } \\
\text { Direto; Benéfico; Baixo grau de impacto }\end{array}$ \\
\hline & $\begin{array}{c}\text { Aumento dos riscos } \\
\text { de doenças por } \\
\text { contaminação da } \\
\text { água**** }\end{array}$ & $\begin{array}{l}\text { Temporário; Local; Reversível; Médio prazo; } \\
\text { Indireto; Adverso; Médio grau de impacto }\end{array}$ \\
\hline
\end{tabular}

*Este impacto foi considerado em virtude da construção de um banheiro no bar, com eliminação dos resíduos no córrego de Lagoa Redonda.

${ }^{* *} A$ redução da biota do solo foi considerada, pois se observou a extração de areia para construções no bar.

***O estudo tratou de qualificar o impacto, entretanto, apesar de positivo, a atividade não é possível de ser realizada, pois não é permitida nesta categoria de unidade de conservação.

****Impacto registrado devido à possível eliminação, no córrego, de coliformes fecais advindos do banheiro construído.

Fonte: Elaborado pelos autores.

A indefinição do polígono gera insegurança jurídica para os gestores na solicitação da retirada dos estabelecimentos, o que contribui para a manutenção e ainda, para o incentivo ao turismo. Ainda assim, necessita-se cautela para efetuar a retirada dos quiosques para que não haja uma intensificação de conflitos com a comunidade. 


\section{Postes de energia elétrica}

Foram encontrados trinta e três postes de energia elétrica na REBIO de Santa Isabel, que abrange uma área de aproximadamente $3 \mathrm{~km}$. Os postes foram instalados a pedido de um proprietário de uma fazenda na unidade. Ressalta-se que não houve autorização do órgão gestor da unidade para a instalação dessas estruturas, e tampouco licença ambiental. Isto culminou, em 2013, em uma ação civil pública ajuizada pelo Ministério Público Federal de Sergipe (MPF/ $\mathrm{SE})$, contra a empresa que instalou os postes e o morador da residência. Na ação foi solicitada a remoção dos postes em 30 dias, com retirada de todo o material. Contudo, a estrutura ainda está instalada de forma total na unidade.

O estabelecimento de pontos luminosos dentro de uma área que serve de sítio reprodutivo para quatro espécies de tartarugas marinhas se torna agravante. A incidência luminosa altera comportamentos noturnos na escolha dos seus sítios de desovas, o retorno para o mar após a postura, e a localização do mar pelos filhos após a saída dos ninhos (WITHERINGTON; MARTIN, 2000). A desorientação dos filhotes no trajeto praia/mar é potencialmente influenciada por luzes de edificação próximas a praia, iluminação pública, de veículos e outras fontes artificiais segundo o texto da Portaria IBAMA no. 11, de 30 de janeiro de 1995 (BRASIL, 1995) (Quadro 6).

Além dos impactos causados pela incidência luminosa, as linhas de energia podem causar eletrocussão e colisão das aves, principalmente se instaladas sem estudos técnicos sobre áreas utilizadas por estes animais (GONZÁLEZ et al., 2014). Sendo a REBIO uma importante área para repouso de aves migratórias, o estabelecimento dos postes torna-se mais crítico ainda.

\section{Quadro 6 - Qualificação dos impactos decorrentes da instalação de postes de energia elétrica na REBIO de Santa Isabel, SE.}

\begin{tabular}{|c|c|c|}
\hline MEIO & IMPACTO & QUALIFICAÇÃO \\
\hline \multirow{4}{*}{ 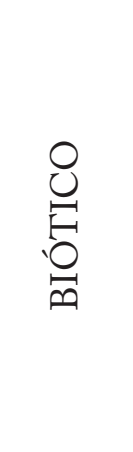 } & $\begin{array}{l}\text { Desorientação de } \\
\text { tartarugas marinhas }\end{array}$ & $\begin{array}{l}\text { Temporário; Local; Irreversível; Curto prazo; } \\
\text { Direto; Adverso; Alto grau de impacto }\end{array}$ \\
\hline & Afugentamento da fauna & $\begin{array}{l}\text { Temporário; Local; Reversível; Curto prazo; } \\
\text { Direto; Adverso; Médio grau de impacto }\end{array}$ \\
\hline & $\begin{array}{l}\text { Eletrocussão e colisão de } \\
\text { aves }\end{array}$ & $\begin{array}{l}\text { Temporário; Local; Irreversível; Curto prazo; } \\
\text { Direto; Adverso; Médio grau de impacto }\end{array}$ \\
\hline & $\begin{array}{l}\text { Alteração da cobertura } \\
\text { vegetal }\end{array}$ & $\begin{array}{l}\text { Temporário; Local; Reversível; Curto prazo; } \\
\text { Direto; Adverso; Médio grau de impacto }\end{array}$ \\
\hline 足 & $\begin{array}{l}\text { Descaracterização da } \\
\text { paisagem }\end{array}$ & $\begin{array}{l}\text { Temporário; Local; Reversível; Curto prazo; } \\
\text { Direto; Adverso; Baixo grau de impacto }\end{array}$ \\
\hline
\end{tabular}

Fonte: Elaborado pelos autores. 


\section{Acúmulo de resíduos sólidos}

Foram identificados dois pontos críticos com maior concentração de lixo (Lagoa Redonda e Ponta dos Mangues) que coincidem com pontos de maior atividade turístico-recreativa. Embora em menor concentração, ao longo da faixa litorânea também foram encontrados resíduos. Os materiais mais comumente encontrados eram constituídos de plástico, como copos descartáveis, garrafas pet e sacolas; ou alumínio, como latas.

Os impactos decorrentes do acúmulo de resíduos sólidos são todos negativos e se estendem para os meios físico, biótico e antrópico. No meio físico, há uma depreciação da qualidade da água, causada pela contaminação dos lençóis freáticos, devido à percolação do chorume, líquido formado da decomposição dos resíduos. Além disto, causa contaminação do ambiente marinho, principalmente por resíduos plásticos que são acumulados na costa, sendo levados para os oceanos através dos movimentos dinâmicos das marés. $\mathrm{O}$ aumento na concentração de gases nocivos, em virtude da liberação de metano e gás sulfídrico é outro impacto ao meio físico (Quadro 7).

Para o meio biótico, os impactos são a contaminação alimentar da fauna terrestre e marinha, que resulta principalmente da ingestão de restos de plásticos (Quadro 7). Segundo Laist (1987), o despejo de resíduos afeta diversas espécies em todo o mundo, sendo as tartarugas marinhas, as aves marinhas e os mamíferos marinhos os mais afetados por esta ação.

\section{Quadro 7 - Qualificação dos impactos decorrentes do acúmulo de resíduos sólidos na REBIO de Santa Isabel, SE.}

\section{MEIO IMPACTOS QUALIFICAÇÃO DOS IMPACTOS}

\begin{tabular}{ccc}
$\underbrace{}_{n}$ & Depreciação da qualidade da água & $\begin{array}{c}\text { Permanente; Local Irreversível; Curto prazo; } \\
\text { Direto; Adverso; Alto grau de impacto }\end{array}$ \\
\cline { 2 - 3 } & $\begin{array}{c}\text { Aumento da concentração de gases } \\
\text { nocivos }\end{array}$ & $\begin{array}{c}\text { Cíclico; Regional; Irreversível; Curto prazo; } \\
\text { Indireto; Adverso; Médio grau de impacto }\end{array}$ \\
\cline { 2 - 3 } & $\begin{array}{c}\text { Contaminação alimentar da fauna } \\
\text { terrestre e marinha; aumento da } \\
\text { mortalidade dos animais. }\end{array}$ & $\begin{array}{c}\text { Temporário; Regional; Reversível; Médio prazo; } \\
\text { Direto; Adverso; Alto grau de impacto }\end{array}$ \\
\cline { 2 - 3 } & Redução da biota do solo & $\begin{array}{c}\text { Temporário; Local; Reversível; Médio prazo; } \\
\text { Indireto; Adverso; Médio grau de impacto }\end{array}$ \\
\hline
\end{tabular}

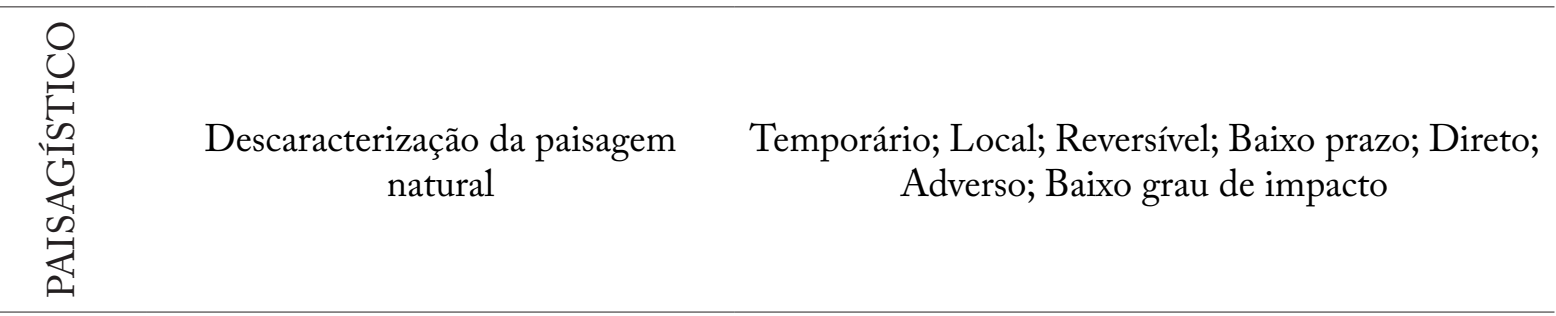


O acúmulo de lixo em ambientes litorâneos traz sérios impactos para a fauna marinha, e diversos estudos científicos apresentam o plástico como um forte agente estressor para aves marinhas (BLIGHT; BURGER, 1997; DERRAIK, 2002; RYAN, 1988); como também para as tartarugas marinhas (CARR, 1987; BUGONI; KRAUSE; PETRY, 2001; TOMÁS et al., 2002; MROSOVSKY et al., 2009). Sendo a área de extrema importância para a conservação de tartarugas marinhas, e destino de descanso e alimentação de aves migratórias da espécie Sterna sp (trinta-réis) (MMA, 2015) torna-se preocupante a presença de lixo na praia, visto que são animais que frequentemente o ingerem de forma acidental.

Haja vista que a deposição de resíduos sólidos no ambiente pode acarretar sérias ameaças para a fauna e flora, recomenda-se que práticas sejam instituídas de forma integrada, pelos órgãos federais e municipais, para uma adequação desta situação, principalmente nos pontos próximos ao Mangue de Ponta dos Mangues, onde se formam verdadeiros "lixões" após períodos festivos ou feriados. Se faz imprescindível um reforço no monitoramento de toda a faixa litorânea da REBIO, que já é executado por monitores da PETROBRAS e Fundação Mamíferos Aquáticos, atuantes na área.

\section{Conclusão}

Diante da constatação das cinco ações impactantes distribuídas por vinte e seis pontos na extensão da REBIO, é possível apontar que a unidade se encontra num cenário de irregularidades, inadequação dos seus objetivos e falta de enquadramento à sua categoria, o que promovem ameaças à sua efetividade como unidade de conservação. Os principais fatores atribuídos a estas ameaças são a ausência da retificação do polígono da unidade e consequente inexistência de regularização fundiária, ausência de plano de manejo, insuficiência de recursos humanos e financeiros, e carência no envolvimento das comunidades com ações de manejo. Os impactos decorrentes das ações se estendem aos meios físico, biótico, antrópico e paisagístico, e seus efeitos agem de forma integrada, resultando em uma alteração dos ecossistemas da REBIO e nos seus serviços ambientais.

O presente estudo constitui-se numa importante ferramenta para direcionar ações de manejo da REBIO de Santa Isabel, em virtude da análise das ações impactantes, bem como para subsidiar futuros estudos que ensejem um aprofundamento de cada ação registrada na pesquisa.

Cabe evidenciar que a REBIO de Santa Isabel enfrenta conflitos em sua gestão, não por falta de leis e normas, e sim por falta de articulação entre as diferentes esferas governamentais e pela falta de estrutura dos órgãos gestores. Ainda que a promoção de unidades de conservação esteja ocorrendo, o seu gerenciamento possui lacunas. Assim, é possível apontar que ainda há uma dificuldade entre a conciliação de políticas de desenvolvimento e conservação do meio ambiente, pois, apesar da importância da instituição da REBIO de Santa Isabel, pouco se destina à sua gestão e efetividade. A deficiência de recursos humanos e financeiros direciona os poucos servidores existentes na UC a enfrentar desafios na implementação e cumprimento dos objetivos para a qual foi criada.

Por conseguinte, faz-se necessário, ademais, a realização de estudos mais aprofundados dos processos culturais, sociais e econômicos das populações envolvidas com a REBIO de Santa Isabel, como forma de traçar possibilidades para minimizar os conflitos entre estes atores envolvidos e, assim, incentivar a participação pública, peça-chave para a conservação da biodiversidade. 


\section{Referências}

ANDRADE et al. Geografia, turismo e educação ambiental no município de PirambuSE: uma estratégia para a valorização da consciência ecológica. Interfaces Científicas - Humanas e Sociais, Aracaju, v.2, n.2, p. 9 - 19, fev. 2014

BENSUSAN, N. Conservação da biodiversidade em áreas protegidas. Rio de Janeiro, Editora FGV, 2006.

BLIGHT, L. K., BURGER, A. E. Occurrence of plastic particles in seabirds from the Eastern North Pacific. Marine Pollution Bulletin, Kidlington, v. 34, n. 5, p. 323-325, 1997

BRASIL. Decreto no 96.999, de 20 de outubro de 1988. Cria, no litoral do Estado de Sergipe, a Reserva Biológica de Santa Isabel e dá outras providências. Brasília/DF, 1988.

BRASIL. Portaria IBAMA no 11, de 30 de janeiro de 1995. Dispõe sobre a iluminação artificial em praias de desova de tartarugas marinhas. Brasília/DF, 1995

BRASIL. Lei no 9.985 de 18 de julho de 2000. Institui o Sistema Nacional de Unidades de Conservação da Natureza - SNUC. Brasília/DF, 2000.

BROWN, A. C.; MCLACHLAN, A. Ecology of sandy shores. Elsevier, Amsterdam, 1990.

BUGONI, L.; KRAUSE, L.; PETRY, M. V. Marine Debris and human impacts on sea turtles in Southern Brazil. Marine Pollution Bulletin. Great Britain: Elsevier Science, v. 42, p.1330-1334, 2001.

CARAMASCHI, U.; PEIXOTO, O. L. A new species of Phyllodytes (Anura: Hylidae) from the state of Sergipe, northeastern Brazil.Amphibia-Reptilia, v. 25, n. 1, p. 1-7, 2004.

CARR, A. Impact of nondegradable marine debris on the ecology and survival outlook of sea turtles. Marine Pollution Bulletin. Great Britain, v. 18, n. 6B, p.352-356, 1987.

CASTILHOS, J. C. et al. Avaliação do estado de conservação da tartaruga marinha Lepidochelys olivacea (Eschscholtz, 1829) no Brasil. Biodiversidade Brasileira, n. 1, 2011.

CAVALCANTI, A. P. B. 2000. Impactos e condições ambientais da zona costeira do Estado do Piauí. Rio Claro (SP): UNESP, 353 f. Tese (Doutorado). Instituto de Geociências e Ciências Exatas, Departamento de Geografia, Universidade Estadual Paulista. Rio Claro (SP)

DERRAIK, J. G. B. The pollution of the marine environment by plastic debris: a review. Wellington: University of Otago.Marine Pollution Bulletin., v. 44, n. 9, p. 842 - 852, 2002. 
DRUMMOND, J. A., O sistema brasileiro de parques nacionais: análise dos resultados de uma política ambiental. Niterói: EDUFF, 1997.

FIGUEIRA, V. Turismo y visitas a las areas protegidas. Breve referencia al Portugal continental. Estudios y Perspectivas en Turismo, 2011, 1214-1232. Disponível em $<$ http://www.scielo.org.ar/pdf/eypt/v20n5/v20n5a14.pdf>. Acesso em: 02 dez. 2015

GANEM, R.S. (Org.). Conservação da biodiversidade: legislação e políticas públicas. Brasília: Câmara dos Deputados, Ed. Câmara, 2010. Série Memória e análise de leis, n. $2,437 \mathrm{p}$.

GONZÁLEZ, G. et al. Medidas de mitigación de impactos en aves silvestres y murciélagos. Servicio Agricola y Ganadero (SAG) y Ministerio de Energia (MINENERGIA), Santiago, Chile, 2014. Disponível em: < https://webdesa.sag.gob. cl>. Acesso em: 12 dez. 2015

HEWETT,D.G. 1985. Grazing and mowing as management tools on dunes vegetation. 62: 441-447.

LAIST, D.W. Overview of the biological effects of lost and discarded plastic debris in the marine environment. Marine Pollution Bulletin, v. 18, n. 6, p. 319-326, 1987.

LICKORISH, L.J. A.;JENKINS, C. L.Un introducción al turismo.P.imprenta: Madrid, España: Síntesis, 2000.

MEDEIROS, R.; IRVING, M.; GARAY, I. A proteção da natureza no Brasil: evolução e conflitos de um modelo em construção. Revista de Desenvolvimento Econômico, v. VI, n. 9, p. 83-93, 2004

MELO, E. A. et al. Conflitos Socioambientais em áreas da Restinga Sergipana: Embates e Perspectivas. Anais do I Seminário Nacional de Geocologia e Planejamento territorial e IV Seminário GEOPLAN, São Cristóvão: Editora UFS, 2011.

MENDES, E. G. et al. Os embates da reestruturação do espaço litorâneo cearense pelo turismo. In: MERCATOR - Ano 1, n.1 (jan / jul 2002). Fortaleza: UFC, 2002.

MMA. Ministério do Meio Ambiente. Secretaria de Biodiversidade e Florestas. Cadastro Nacional de Unidades de Conservação. Relatório Parametrizado da Reserva Biológica de Santa Isabel, 2015. Disponível em <http://www.mma.gov.br/areas-protegidas/ cadastro-nacional-de-ucs $>$. Acesso em: 02 jun. 2015

.Instituto Chico Mendes de Conservação da Biodiversidade. Roteiro metodológico de planejamento: Parque Nacional, Reserva Biológica, Estação Ecológica, 2002. Disponível em <http://www.icmbio.gov.br/portal/images/stories/imgs-unidadescoservacao/roteiroparna.pdf $>$. Acesso em: 18 dez. 2015. 
MONTREAL. Secretaría del Convenio sobre la Diversidad Biológica. Programa de Trabajo sobre Áreas Protegidas (Programas de trajabo del CDB). 34p., 2004

MROSOVSKY, N.; RYAN, G. D.; JAMES, M. C. Leather back turtles: The menace of plastic. Marine Pollution Bulletin. v. 58, p. 287-289, 2009

OLIVEIRA, A. C. A.; SOUZA, R. M. Risco ambiental em dunas costeiras de Sergipe, Brasil. In: X Encontro de Geógrafos da América Latina, 2005, São Paulo. Anais... Universidade de São Paulo, p.46-65, 2005.

OLIVEIRA, A.C.A.; SOUZA, R. M. Ecodinâmica dos sistemas dunares do município de Pirambu, litoral norte de Sergipe. Sociedade e Território, v. 23, n. 2, p. 2-20, 2012.

PÁDUA, M. T.J. Sistema brasileiro de unidades de conservação: de onde viemos e para onde vamos. In: Anais Congresso Brasileiro de Unidades de Conservação. p. 15-23, 1997.

PÁDUA, M.T.J. Do sistema nacional de unidades de conservação. In: MEDEIROS, R.; ARAÚJO, F. F. S (Ed.). Dez anos do Sistema Nacional de Unidades de Conservação da Natureza: lições do passado, realizações presentes e perspectivas para o futuro. Brasília: MMA, p. 23-36, 2011.

ROSA, L.S.; CORDAZZO, C.V.Perturbações antrópicas na vegetação das dunas da praia do cassino (RS). Cadernos de Ecologia Aquática (2):1-12, 2007. Universidade Federal do Rio Grande (FURG), Rio Grande, RS, Brasil. Disponível em <http://www.cadernos. ecologia.furg.br/images/artigos/16_Rosa\&Cordazzo.pdf. Acesso em: 18 dez. 2015

RYAN, P. G. Effects of ingested plastic on seabird feeding: evidence from chickens. Marine Pollution Bulletin, v. 19, n. 3, p. 125-128, 1988. Disponível em: < https://www. sciencedirect.com/science/article/pii/0025326X88907084>. Acesso em: 02 jan. 2016

SANTOS, R. F. Planejamento Ambiental: teoria e prática. São Paulo: Oficina de Textos, 2007

SANTOS, A. S. et. al. Plano de ação nacional para a conservação das Tartarugas Marinhas- Brasília : Instituto Chico Mendes de Conservação da Biodiversidade, ICMBio, 2011. $120 \mathrm{p}$

SANTOS, L. I. et al. Identificação das ações impactantes na Área de Proteção Ambiental Morro do Urubu, Aracaju-SE. Scientia Plena, v. 9, n. 10, 2013.

SAUNDERS, C. et al. A review of the effects of recreational interactions within UK European marine sites. UK CEED Marine in association with Bournemouth University, Centre for Coastal Conservation and Education, 265 p., 2000

SOBRAL, I. S. et al. Avaliação dos impactos ambientais no Parque Nacional Serra de 
Itabaiana SE. Caminhos de Geografia (UFU), v. 8, p. 102-110, 2007

SPERA, S. T. et al. Solos areno-quartzosos no Cerrado: problemas, características e limitações ao uso. Planaltina: Embrapa Cerrados, 48p. 1999.

SUZANNE, C. Globo, Jornal Hoje. Turistas se encantam com lagoas e praias de Pacatuba (SE). 2014.Disponível em: < $\underline{\text { http://g1.globo.com/jornal-hoje/noticia/2014/10/ }}$ turistas-se-encantam-com-lagoas-e-praias-de-pacatuba-se.html> Acesso em: 10 jan. 2016

TOMÁS, J. et al. Marine debris ingestion in logger head sea turtles, Caretta caretta from the Western Mediterranean. Marine Pollution Bulletin. v.44, n. 3, p. 211-216, 2002.

WITHERINGTON, B. E.; MARTIN, R. E. Understanding, Assessing, and Resolving Light-Pollution Problems on Sea Turtle Nesting Beaches. St. Petersburg, FL, Florida Marine Research Institute, (Florida Marine Research Institute. Technical Report, TR2), 2000 . 